\title{
Ex vivo phagocytic overall performance of neutrophilic granulocytes and the relation to plasma insulin-like growth factor-I concentrations in dairy cows during the transition period
}

\author{
A. K. Sander, ${ }^{\star 1}$ M. Piechotta, ${ }^{* 1}$ G. Schlamberger,† H. Bollwein, ${ }^{*}$ M. Kaske, ${ }^{*}$ A. Sipka, $\neq$ and H. J. Schuberth $\ddagger^{2}$ \\ ${ }^{*}$ Clinic for Cattle, University of Veterinary Medicine, Hannover, Bischofsholer Damm 15, 30173 Hannover, Germany \\ †Physiology Weihenstephan, Technische Universität München, Weihenstephaner Berg 3, Freising-Weihenstephan, 85354 Germany \\ ‡Immunology Unit, University of Veterinary Medicine, Hannover, Bischofsholer Damm 15, 30173 Hannover, Germany
}

\begin{abstract}
Impaired function of polymorphonuclear neutrophilic leukocyte (PMNL) during the peripartal period is a major reason for increased susceptibility of dairy cows to infections in this critical interval. Factors dysregulating PMNL function are widely unknown. Insulin-like growth factor (IGF-I) enhanced PMNL functions in vitro. The objective of this study was to investigate the influence of IGF-I and, additionally, $\beta$-hydroxybutyrate and nonesterified fatty acid concentrations on phagocytic activity (PA, percentage of viable PMNL) and phagocytic capacity (PC, mean fluorescence intensity of phagocytic PMNL) assessed by flow cytometry. Antepartum (i.e., wk $-3,-2,-1$; before calving), plasma concentrations of IGF-I were high $(80-110 \mathrm{ng} / \mathrm{mL})$ without significant differences between primiparous and pluriparous cows ( $\mathrm{n}=18$ and $\mathrm{n}=41$, respectively). Concentrations of IGF-I declined toward the week of calving (wk 1). Postpartum (i.e., wk 2, 3, and 4; after calving), IGF-I remained lower than before parturition, with concentrations higher in primiparous compared with those of pluriparous cows. The PA was constant in primiparous cows throughout the study period. Conversely, PMNL of pluriparous cows had a significantly increased and higher PA in wk 2 and 3 postpartum compared with that of primiparous cows. The PC decreased significantly only in primiparous cows the week of calving, whereas the number of PMNL in primiparous cows exceeded that of pluriparous cows significantly. The phagocytic power (PP, a product of PA by $\mathrm{PC}$ ), but not the phagocytic overall performance (POP, a product of $\mathrm{PA}, \mathrm{PC}$, and PMNL number), differed between primiparous and pluriparous cows in wk 3 postpartum. No significant differences in POP were found, except in wk 4 after calving between the primi- and pluriparous cows. In both groups, POP increased in the week of calving (wk
\end{abstract}

Received March 19, 2010.

Accepted October 14, 2010.

${ }^{1}$ Both authors contributed equally to this work.

${ }^{2}$ Corresponding author: hans-joachim.schuberth@tiho-hannover.de
1). In contrast to $\beta$-hydroxybutyrate, which was weakly positive correlated with PA and PP in pluriparous cows in the transition period ( $w \mathrm{k}-3$ antepartum to wk 4 postpartum), pluriparous animals had weak negative correlations of PMNL number, PA, PP, POP, and IGF-I concentration in this period. In primiparous animals, only $\mathrm{PP}$ and $\mathrm{PC}$ were weakly negatively correlated with IGF-I in the transition period. Increased plasma IGF-I concentrations were not associated with enhanced phagocytosis function of bovine blood PMNL ex vivo and, thus, can not be regarded as a suitable predictor for this function.

Key words: insulin-like growth factor (IGF-I), polymorphonuclear neutrophilic leukocyte (PMNL), transition period, immune suppression

\section{INTRODUCTION}

Peripartal diseases are very common in high-yielding dairy cows and result in major economic losses. The transition period has a great effect upon subsequent production, fertility, and health. The classical view is that immunity is suppressed or skewed toward antiinflammatory reactions during gestation and that the peripartal period is generally associated with an immune suppression (Van Kampen and Mallard, 1997), which predisposes the cows to infectious diseases (Mehrzad et al., 2009).

Polymorphonuclear neutrophilic leukocytes play a decisive role in eliminating invading bacteria; their phagocytic and bactericidal function is pivotal for host defense (Smits et al., 1997). In dairy cows, pregnancy and lactation are associated with impaired functions of PMNL and lymphocytes (Kehrli et al., 1989; Sheldon et al., 2009). The transition from pregnancy to calving is also accompanied by a gradual decrease of PMNL bactericidal capacity (Hoeben et al., 2000). Furthermore, viability of blood PMNL was significantly higher in primiparous cows compared with that in pluriparous cows (Mehrzad et al., 2002). Based on decreased PMNL viability and production capacity of free radicals in pluriparous cows, it was suggested that they had less 
protection than primiparous cows against pathogenic bacteria (Mehrzad et al., 2009).

Endocrine and metabolic changes around calving may modulate PMNL phagocytic function (Madsen et al., 2002; Burvenich et al., 2007). In vitro, NEFA, BHBA, and 17ß-estradiol decrease phagocytic capacity and viability of PMNL, whereas these functions were not affected by progesterone or dexamethasone (Lamote et al., 2004; Scalia et al., 2006). However, in vivo, no significant correlations existed between steroid hormones and PMNL function. Also, elevated concentrations of NEFA and BHBA during the transition period seemed not to affect PMNL function (chemotaxis) in vivo (Loiselle et al. 2009). One of various endocrine changes in the transition period is the $70 \%$ decrease in plasma IGF-I concentrations after calving (Taylor et al., 2004), facilitating the mobilization of amino acids from skeletal muscle in support of hepatic gluconeogenesis (Boisclair et al., 1994; Bell, 1995). Plasma IGF-I concentrations were higher in primiparous cows compared with those of pluriparous cows. Lower IGF-I concentrations postpartum were associated with a longer calving to conception interval and failures to conceive (Taylor et al., 2004). Cows with severe negative energy balance (NEB) and lower IGF-I concentrations postpartum had decreased numbers of white blood cells and lymphocytes (Wathes et al., 2009). In vitro, IGF-I increased the phagocytosis of both IgG-opsonized Staphylococcus aureus and complement-opsonized Candida albicans by human PMNL (Bjerknes and Aarskog, 1995). In addition, IGF-I increased complement receptor expression on PMNL and their oxidative burst (Bjerknes and Aarskog, 1995; Inoue et al., 1998). Moreover, IGF-I inhibited spontaneous apoptosis of granulocytes in serum-free cultures of human granulocytes by 32 to $45 \%$. Therefore, IGF-I may promote granulocyte functions by increasing granulocyte longevity (Kooijman et al., 2002). In contrast, intraperitoneal administration of IGF-I in mice inhibited gastric accumulation of PMNL by inhibition of caspase-3-mediated endothelial monocyte-activating polypeptide-II activation (Zhao et al., 2009). Comparable results were obtained in piglets (Balteskard et al., 1998). Pretreatment of piglets with IGF-I infusion suppressed the ability of PMNL to phagocytose bacteria under nonseptic conditions. However, in human neutrophils, in vitro priming with IGF-I enhanced both phagocytosis and the respiratory burst (Inoue et al., 1998). However, in vitro studies regarding the effects of IGF-I on bovine PMNL have apparently not been reported.

Based on the premise that IGF-I may influence not only the number but also the function of bovine PMNL during the transition period in dairy cows, the objectives of this study were to (a) determine the effects of pregnancy, calving, and early lactation on PMNL phagocytic activity (PA) and phagocytic capacity (PC) in primiparous and pluriparous cows, and (b) determine the correlations between IGF-I, NEFA, and BHBA plasma concentrations and PMNL phagocytic activity and capacity.

\section{MATERIALS AND METHODS}

\section{Animals and Management}

A total of 59 dairy cows [48 Holstein-Friesian (HF) and 11 crossbreds of Brown-Swiss $\times$ HF; 18 primiparous, 41 pluriparous] at the Hannover University Farm were used. This study was approved and conducted in accordance with German legislation on animal rights and welfare.

All pluriparous cows were dried off approximately 6 wk before the predicted calving date and were grouped together with the primiparous cows in a cubicle housing system fitted with a slatted floor. Nonlactating cows were fed a grass silage-based partly mixed ration blended with $5 \%$ of chopped straw $\left(6.2 \mathrm{MJ}\right.$ of $\mathrm{NE}_{\mathrm{L}} / \mathrm{kg}$ of DM, $12.9 \%$ of CP). About 2 to 1 wk before the predicted calving day, cows were grouped in a transition area and fed a partly mixed ration. Additionally, cows were fed $1 \mathrm{~kg}$ of concentrate three times daily. Calving in straw-bedded maternity pens was uncomplicated in almost all cases; obstetrical assistance did not exceed moderate intervention. After calving, the primiparous (HF, $\mathrm{n}=18 ; 2.0-3.2 \mathrm{yr}$ ) and pluriparous cows (HF, $\mathrm{n}=30$; Brown-Swiss $\times \mathrm{HF}, \mathrm{n}=11 ; 2$ nd -5 th lactation, 3.2-8.8 yr) were housed either in a straw yard and milked in a milking parlor twice daily or in a cubicle housing system fitted with slatted floors and milked by a milking robot.

All lactating cows were fed a partly mixed ration (47.9\% of corn silage, $39.7 \%$ of grass silage, $9.9 \%$ of soy meal, $2.5 \%$ of sugar beet crop) providing $6.9 \mathrm{MJ}$ of $\mathrm{NE}_{\mathrm{L}} / \mathrm{kg}$ of DM and $12.2 \%$ of CP.

The partly mixed ration was formulated on the basis of a milk yield of $>23 \mathrm{~kg} / \mathrm{d}$ and was provided to allow ad libitum intake. Cows producing more than $23 \mathrm{~kg} / \mathrm{d}$ were fed additional concentrates $(0.5 \mathrm{~kg}$ of concentrate/ $\mathrm{kg}$ of milk; maximal $9 \mathrm{~kg} / \mathrm{d}$; Raiffeisen Kraftfutterwerke, Braunschweig, Germany) in feeding stations.

\section{Blood Sampling}

Blood samples were collected by jugular venipuncture into serum tubes and tubes containing sodiumheparin (BD Vacutainer Systems, Plymouth, UK) and potassium-EDTA (Sarstedt, Nürnbrecht, Germany) as anticoagulants. 
The clinical status of the cows was monitored daily by the farm staff. If a marked reduction of milk yield or a reduced intake of concentrate occurred, a veterinarian was consulted. If a production disease was diagnosed after clinical investigation, the results of the corresponding blood sample of this respective cow were excluded from further data analyses.

Starting $240 \mathrm{~d}$ after the artificial insemination that initiated pregnancy, blood sampling was done between 0600 to $1000 \mathrm{~h}$ every $7 \mathrm{~d}$. In retrospect, blood samples were sorted by the calving date (wk $-3: \mathrm{d}-21$ to -15 antepartum, a.p.; wk -2 : $\mathrm{d}-14$ to -8 a.p.; and wk -1 : $\mathrm{d}-7$ to -1 a.p.); the week of calving (wk 1: $\mathrm{d} 0$ to $6 \mathrm{~d}$ postpartum, p.p.); and wk 2 (7 to 11 d p.p.), wk 3 (12 to 18 d p.p.), and wk 4 (19 to 26 d p.p.) after calving.

The EDTA plasma and serum were cooled down immediately on ice and centrifuged $(1,600 \times g$ for $20 \mathrm{~min})$. The plasma was kept frozen at $-20^{\circ} \mathrm{C}$ until analyzed for blood parameters. Sodium-heparin blood samples were kept at room temperature. Phagocytic activity and capacity of neutrophilic granulocytes were assessed within $3 \mathrm{~h}$ after blood sampling.

\section{Determination of IGF-I Concentrations in Plasma}

For total plasma IGF-I determination, an ACTIVE IGF-I coated tube immunoradiometric assay (DSL5600, Diagnostic Systems Laboratories, Inc., Webster, TX) was used. Separation of IGF-I from its binding proteins was done by an acid-ethanol extraction procedure and IGF-I concentrations were determined with a 2-site immunoradiometric assay. The intra-and interassay coefficients of variation were 1.5 to 3.5 and 1.5 to $8.5 \%$, respectively.

\section{Determination of BHBA and NEFA Concentration}

Serum concentrations of NEFA and BHBA were determined with an automated clinical chemistry analyzer (ABX Pentra 400, Horiba, Montpellier, France) using colorimetric enzymatic reactions for NEFA concentration (CV 6.2\%), whereas BHBA concentration was determined using a spectrophotometric enzymatic analysis (Sigma-Aldrich Diagnostics, Munich, Germany; CV $7.1 \%)$.

\section{Total and Differential Leukocyte Counts}

The number of circulating PMNL was counted by an electronic cell counter (Celltac, Nihon Kohden, Rosbach, v.d.H., Germany). Differential leukocyte counts (percentages of subpopulations among all leukocytes) were determined by differentiating 100 cells using blood smears stained with May-Grünwald-Giemsa (Merck, Darmstadt, Germany) with light microscopy. Numbers of PMNL/mL of blood were calculated as \% of PMNL $\times$ total leukocytes.

\section{Determination of Phagocytic Activity and Phagocytic Capacity}

Nonviable Staph. aureus in suspension (Pansorbin, Calbiochem, Merck, Nottingham, UK) were labeled with fluorescein isothiocyanate (FITC, Sigma-Aldrich, St. Louis, MO). The FITC-labeled Staph. aureus were centrifuged at $14,000 \times g$ for 1 min. Pelleted bacteria were resuspended in PBS and centrifuged again. This procedure was repeated twice. Finally, bacteria were adjusted to $2 \times 10^{8}$ cells $/ \mathrm{mL}$ of PBS.

Flow cytometer tubes (Becton Dickinson Biosciences, Plymouth, UK) were filled with $100 \mu \mathrm{L}$ of heparinized whole blood, and $50 \mu \mathrm{L}$ of FITC-labeled bacteria suspension $\left(1 \times 10^{7}\right.$ bacteria) were added. The mixture was incubated for 30 min at $37^{\circ} \mathrm{C}$ and $5 \%$ of $\mathrm{CO}_{2}$. Erythrocytes were lysed by adding $2 \mathrm{~mL}$ of double-distilled water for $20 \mathrm{~s}$, followed by the addition of $2 \mathrm{~mL}$ of double-concentrated PBS. Leukocytes were centrifuged $(14,000 \times g)$ for $10 \mathrm{~min}$, the supernatant discarded and resuspended in $300 \mu \mathrm{L}$ of sterile-filtered PBS containing $2 \mu \mathrm{g} / \mathrm{mL}$ of propidium iodide.

Cells were analyzed using a particle counter (Coulter counter, Coulter Electronics Ltd., Luton, UK). The data were collected with FACStation using the software CellQuest (Becton Dickinson Biosciences). Ten thousand events were acquired.

Viable PMNL were identified after gating on events with characteristic forward and side scatter values that were negative for propidium iodide fluorescence. Polymorphonuclear neutrophilic leukocytes with ingested bacteria were identified as gated events with increased green fluorescence. The PA was defined as the percentage of green fluorescing PMNL among viable PMNL. The PC was defined as the mean fluorescence intensity of green fluorescing PMNL. The phagocytic power $(\mathbf{P P})$ was defined as the product of PA by PC, specifying the amount of ingested bacteria by a given PMNL population. The phagocytic overall performance (POP) was defined as the product of the PP by the absolute number of PMNL present in a given assay.

\section{Statistical Analysis}

Data were analyzed using REML in the MIXED procedure in SAS (version 2002; SAS Institute Inc., Cary, $\mathrm{NC}$ ). The model contained fixed effects of parity and week, and their interactions. Because data were col- 
lected longitudinally, data points were correlated within each cow; therefore, cow was included in the analysis as a random effect The specified term for the repeated statement was week, subject was cow (parity), and because all outcomes evaluated were biological samples collected at consistent intervals, the covariance structure used was first-order autoregressive, which provided the best fit for these analyses according to the Akaike information criterion (Littell et al., 1998). Differences between parity were determined using the PDIFF option. Results are reported as least squares means \pm standard error of the means. Means were considered to differ significantly in the case of $P<0.05$. Correlations were performed with SigmaStat 2.0 software and tested using the Pearson product moment correlation, or, in case of not normally distributed data, the Spearman rank order test. Correlations were tested between blood parameters (IGF-I, NEFA, and BHBA) and PMNL parameters (number, PA, PC, PP, and POP) both for primiparous and pluriparous cows, each for 2 time periods (antepartum and postpartum) as well as for the transition period defined as wk 3 a.p. to wk 4 p.p. A $P$-value of $<0.05$ was designated to be significant.

\section{RESULTS}

\section{Animals}

A total of 413 blood samples was collected from 59 dairy cows. Forty-three blood samples were excluded from the analyses due to production diseases (i. e., 5 samples in wk -3 , one in wk $-2,3$ in wk $-1,16$ in wk 2,10 in wk 3 , and 8 in wk 4). Retained fetal membrane/metritis was diagnosed 15 times, hypocalcaemia 10 times, primary ketosis or abomasal displacement 6 times, and mastitis 10 times. One blood sample from each of 41 cows was omitted and 2 samples were discarded from 2 cows. Thus, complete data sets were available from 18 cows.

No differences in blood parameters (IGF-I, NEFA, BHBA) or PMNL function were obvious between 48 $\mathrm{HF}$ and 11 crossbreds of Brown-Swiss $\times \mathrm{HF}$, used in this study.

\section{Plasma IGF-I Concentrations}

Plasma IGF-I concentrations were significantly higher antepartum (wk $-3,-2,-1)$ compared with those during the week of calving (wk 1), but were not significantly different between primiparous and pluriparous cows antepartum. Postpartum (wk 1 to 4 ) IGF-I concentrations were significantly higher in primiparous than in pluriparous cows (Figure 1a).
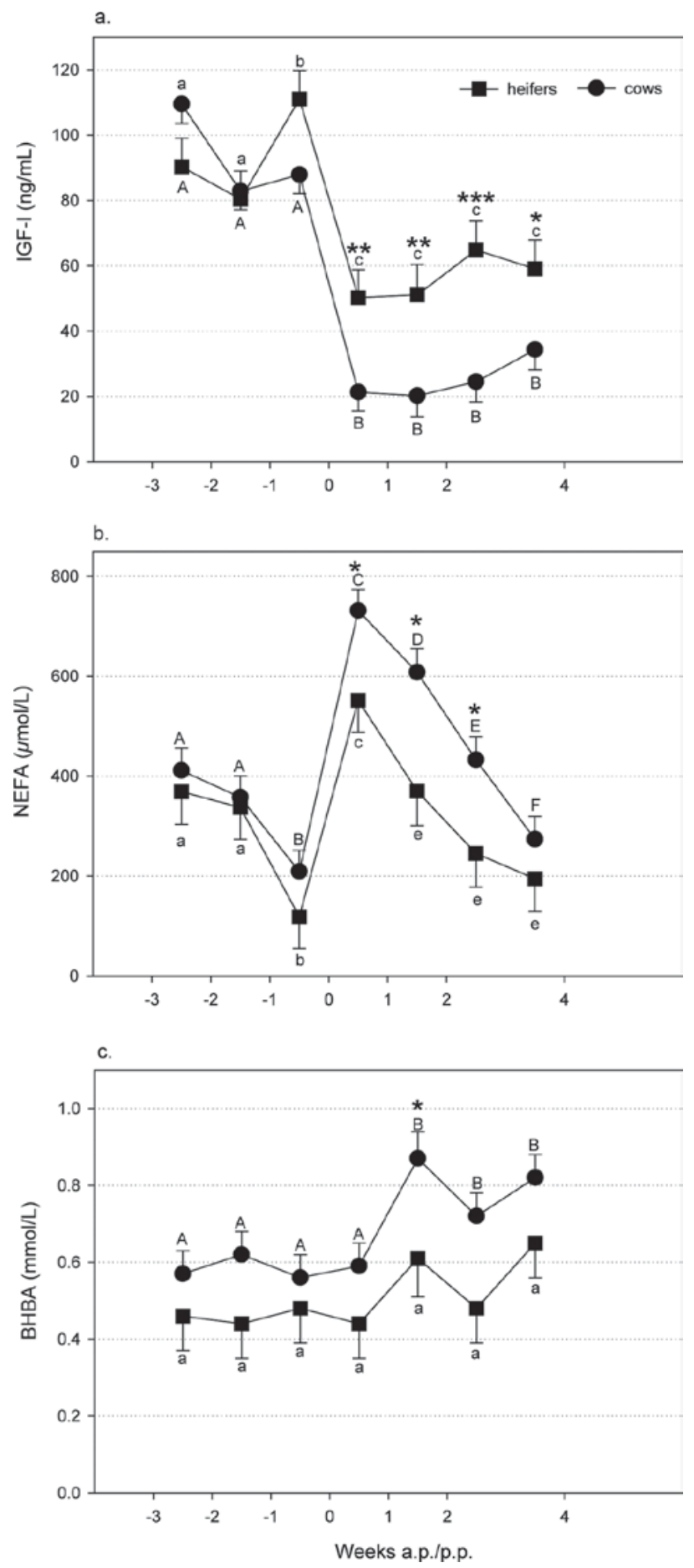

Figure 1. Plasma concentrations of a) IGF-I, b) NEFA, and c) BHBA in primiparous (heifers, $\mathbf{0})$ and pluriparous (cows, $\bullet$ ) animals from wk -3 to 4 (LSM \pm SEM). Weeks -3 to -1 are antepartum (a.p.) and weeks 1 to 4 are postpartum (p.p.). Asterisks indicate significant differences between primiparous and pluriparous animals ${ }^{*} P$ $\left.<0.05,{ }^{* *} P<0.01,{ }^{* * *} P<0.001\right)$. Different letters indicate significant differences among consecutive weeks; uppercase letters indicate cows $(\mathbf{)}$ ) l lowercase letters indicate heifers $(\boldsymbol{\square})$. Number of animals in each week: $-3=$ heifers: 17 , cows: $37 ;-2=$ heifers: 18 , cows: $40 ;-1$ $=$ heifers: 17 , cows: $39 ; 1=$ heifers: 18 , cows: $41 ; 2=$ heifers: 14 , cows: $29 ; 3=$ heifers: 16 , cows: $33 ; 4=$ heifers: 17 , cows: 34 . 


\section{Plasma NEFA and BHBA Concentrations}

Blood NEFA concentrations did not differ significantly between primi- and pluriparous cows antepartum. In both parity groups, NEFA concentrations increased significantly between wk -1 and 1 . After calving, NEFA concentration decreased progressively in both groups. During wk 1-2 after calving, however, primiparous animals had significantly higher concentrations than did pluriparous cows (Figure 1b).

Plasma BHBA concentrations were comparable between primi- and pluriparous cows ante- and postpartum except at wk 2 p.p., when pluriparous cows had a significantly higher BHBA concentration compared with that of primiparous cows (Figure 1c).

\section{Blood Neutrophilic Granulocyte Counts}

In both primiparous and pluriparous cows, blood PMNL counts increased significantly in wk 1 compared with the antepartal blood PMNL counts (Figure 2a). In the peripartum period, primiparous cows had higher PMNL counts $(11,393 \pm 904 \mathrm{PMNL} / \mu \mathrm{L}$ of blood $)$ compared with those of pluriparous cows $(8,670 \pm 614$ PMNL $/ \mu \mathrm{L}$ of blood; $P=0.013)$. The PMNL counts increased in primiparous cows in wk 3 , whereas in pluriparous cows, a significant increase was observed in wk 4. In wk 3, primiparous cows had significantly higher PMNL counts compared with those of pluriparous cows. In contrast, pluriparous cows had significantly higher PMNL counts in wk 4 (Figure 2a).

\section{Phagocytic Activity and Capacity}

The PA did not differ between primiparous and pluriparous cows antepartum (wk $-3,-2,-1$ ) and in wk 1 (Figure 2b). In pluriparous cows, but not in primiparous cows, PA increased significantly from wk 1 to 2 p.p. In wk 2 and 3 p.p., the PA of pluriparous cows significantly exceeded that of primiparous cows.

The PC was comparable between primiparous and pluriparous cows throughout the study. In both parities, a significant increase of $\mathrm{PC}$ occurred in wk 2 (Figure 2c).

\section{Phagocytic Power and Overall Performance}

The PP tended to be higher in pluriparous than in primiparous cows (wk $-3: P=0.089$; wk $-2: P=$ 0.244 ; wk $-1: P=0.680$; wk $1: P=0.485$; wk $2: P=$ 0.800 ; wk $4: P=0.222$ ), reaching a level of significance, however, only in wk 3 p.p. $(P=0.0473$; Figure $2 d)$. In primiparous and pluriparous cows, $\mathrm{PP}$ increased significantly from wk 1 to 2 p.p. and remained on an overall higher level than a.p. (Figure 2d).
The POP increased from wk -1 to 1 in primiparous and pluriparous cows $(P \leq 0.001)$, followed by a significant decrease (wk 2;P<0.001). In primiparous cows, POP significantly increased from wk 2 to 3 p.p. $(P=0.049)$. In wk 4 , POP was significantly higher in pluriparous cows compared with that of primiparous cows $(P<0.001)$. The POP was comparable between primiparous and pluriparous cows throughout the period tested, except in wk 4 p.p. (Figure 2e).

\section{Correlations Between IGF-I, NEFA, and BHBA Concentrations and PMNL Function}

For primiparous and pluriparous animals, correlations were calculated for the transition period and defined time periods (a.p., calving, and p.p.). Significant correlation coefficients are shown in Table 1. Positive correlations between $\mathrm{BHBA}$ and $\mathrm{PA} / \mathrm{PP}$ were only observed in pluriparous cows. Most of the significant correlations were between IGF-I and the various PMNL end points. In pluriparous cows only, POP, PA, PP, and PMNL were all negatively correlated with IGF-I during the transition period, whereas in primiparous cows only PC and PP were negatively correlated with IGF-I in this period.

\section{DISCUSSION}

Impaired PMNL function during the peripartal period depends on a variety of humoral and cellular factors and is regarded as a major reason for an increased susceptibility of dairy cows to infections. Fatty liver and NEB were associated with impaired peripheral blood neutrophil function (Zerbe et al., 2000; Hammon et al., 2006). In primiparous cows, fewer factors are known to affect immunity in early lactation (Piepers et al., 2009). Plasma concentrations of IGF-I were decreased during NEB and further declined, reaching a nadir at calving (Lucy, 2000; Wathes et al., 2009).

Primiparous cows with ongoing growth during pregnancy and first lactation had higher IGF-I concentrations than did pluriparous cows (Taylor et al., 2004), providing a rational approach for the comparison of primiparous with pluriparous cows during the peripartal period. Absolute IGF-I concentrations and the characteristic decrease in IGF-I concentrations around calving were comparable to results of other studies (Mallard et al., 1997; Taylor et al., 2004; Kawashima et al., 2007).

Because in vitro studies suggested that IGF-I enhanced PMNL functions (Bjerknes and Aarskog, 1995; Inoue et al., 1998; Kooijman et al., 2002) we addressed the hypothesis that IGF-I plasma concentrations were predictive for PMNL function between wk -3 a.p. and wk 4 p.p. in primiparous and pluriparous cows. 

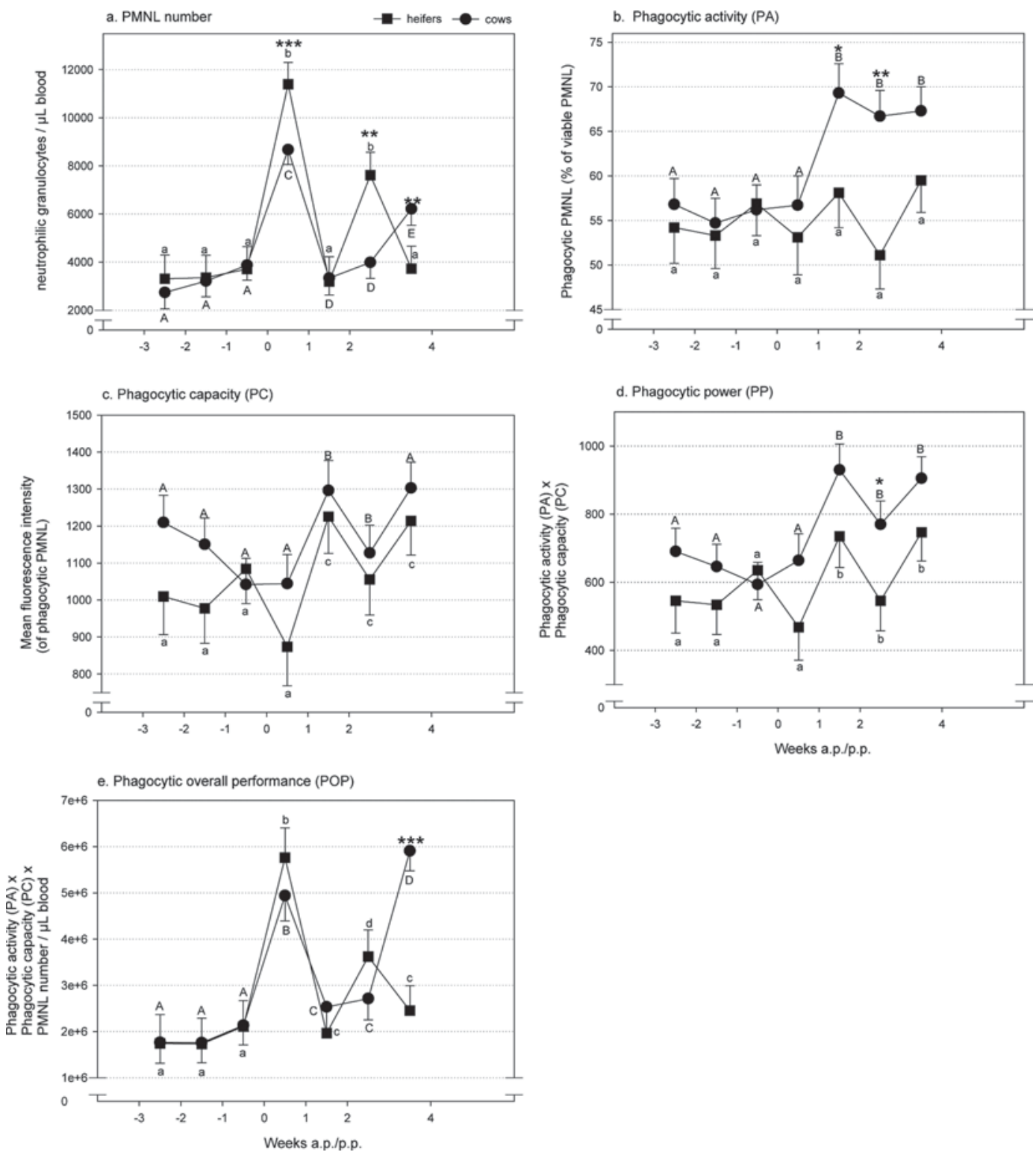

Figure 2. a) Numbers of PMNL per microliter of blood in primiparous (heifers, $\mathbf{0}$ ) and pluriparous (cows, $\bullet$ ) animals from wk -3 to 4 ; b) phagocytic activity (PA, defined as $\%$ of viable PMNL); c) phagocytic capacity (PC, defined as mean fluorescence intensity of phagocytic PMNL) of PMNL from primiparous and pluriparous animals; d) phagocytic power (PP, defined as phagocytic activity $\times$ phagocytic capacity); and e) phagocytic overall performance $(\mathrm{POP}$, defined as phagocytic activity $\times$ phagocytic capacity $\times$ PMNL number) of bovine PMNL from primiparous and pluriparous animals. Weeks -3 to -1 are antepartum (a.p.) and weeks 1 to 4 are postpartum (p.p.).Values are least squares means \pm standard error of the means. Asterisks indicate significant differences between primiparous and pluriparous animals $\left(* P<0.05\right.$, ${ }^{*} P$ $\left.<0.01,{ }^{* * *} P<0.001\right)$. Different letters indicate significant differences among consecutive weeks; uppercase letters indicate cows $(\bullet)$; lowercase letters indicate heifers $(\boldsymbol{\square})$. Number of animals in each week: $-3=$ heifers: 17 , cows: $37 ;-2=$ heifers: 18 , cows: $40 ;-1=$ heifers: 17 , cows: 39 ; $1=$ heifers: 18 , cows: $41 ; 2=$ heifers: 14 , cows: $29 ; 3=$ heifers: 16 , cows: $33 ; 4=$ heifers: 17 , cows: 34.

\section{IGF-I Around Calving}

The previously reported higher IGF-I concentrations in primiparous cows in wk -1 a.p. (Taylor et al., 2004) could not be confirmed (Figure 1a), which might be due to differences in feeding regimen or to fewer cows being used in our study. In agreement with results from Taylor et al. (2004), IGF-I concentrations p.p. (wk 1-4) were significantly higher in primiparous than in pluriparous cows.

\section{PMNL Function Around Calving}

During the transition period, neutrophils are believed to have fewer functional capacities (Kehrli et al., 1989; Hoeben et al., 2000), although others found no 
evidence for selected functions such as phagocytosis, either of midlactating or periparturient cows (Meglia et al., 2005; Scalia et al., 2006; Loiselle et al. 2009). Most of the reported studies using phagocytosis assays have been done with neutrophils derived and separated from peripheral blood, or with purified leukocyte preparations (Hogan et al., 1990; Scalia et al., 2006; Loiselle et al., 2009; Mehrzad et al., 2009) to which either microspheres or bacteria were added in various bacteria:PMNL ratios. Bacteria or microspheres were sometimes opsonized with pooled bovine serum. Only rarely were full blood assays employed, as in the present study (Meglia et al., 2005).

The advantage of full blood assays is that phagocytosis depends not only on the intrinsic capability of the cells of an animal but also on the presence and concentration of opsonizing factors. Thus, the values obtained with full blood assays reflect more closely the individual capability to phagocytose. The drawback of full blood assays, however, is that these tests are not standardizable due to the fact that cell numbers can differ between days of sampling and between animals.

The respective number of bacteria that can be phagocytosed by cells in a given amount of blood is determined by the fraction of phagocytosing neutrophils (PA), the mean uptake of bacteria per cell (PC), and by the number of PMNL (Figure 2e). When combining $\mathrm{PA}, \mathrm{PC}$, and neutrophil numbers into the POP, primiparous and pluriparous cows did not differ significantly with respect to PMNL function in the week of calving. The peak of POP overlapped with the time of maximal neutrophil numbers (Figure 2a, 2e). Although primiparous cows displayed an apparently lower PA after calving and a significant drop in PC (Figure 2b), this obviously was compensated in the full blood compartment by higher blood PMNL numbers.

For the phagocytosis assay, we expected differences between samples with higher or lower neutrophil numbers $/ \mathrm{mL}$ of blood due to different bacteria:PMNL ratios. Higher PMNL numbers, together with a fixed number of added bacteria, and such a low bacteria:PMNL ratio should result in a decreased phagocytosis. The most prominent increase in PMNL numbers occurred as expected in the week of parturition (Figure 2a), both in pluriparous and primiparous cows. However, based on the fraction of neutrophils which phagocytosed bacteria, only pluriparous cows but not primiparous cows displayed a significantly enhanced PA (Figure $2 \mathrm{~b}$ ), although primiparous cows showed an even more pronounced increase in neutrophil numbers. Strikingly, the PA remained at significantly higher levels in cows (compared with those of heifers) at later times after parturition, despite the fact that during this time the
Table 1. Significant correlations between blood (IGF-I, NEFA, and BHBA) and PMNL parameters of primi- and pluriparous cows

\begin{tabular}{llrl}
\hline Group & Comparison $^{1}$ & R-value & $P$-value \\
\hline Primiparous & & & \\
Antepartum & NEFA vs. PA & 0.346 & 0.020 \\
Calving & IGF-I vs. PA & -0.264 & 0.017 \\
Postpartum & IGF-I vs. PC & -0.242 & 0.022 \\
Transition period & IGF-I vs. PC & -0.272 & 0.0056 \\
& IGF-I vs. PP & -0.232 & 0.019 \\
Pluriparous & & & \\
Antepartum & BHBA vs. PA & 0.244 & 0.027 \\
Postpartum & NEFA vs. PMNL & -0.218 & 0.034 \\
Transition period & IGF-I vs. PMNL & -0.231 & 0.00035 \\
& IGF-I vs. PA & -0.239 & 0.0016 \\
& IGF-I vs. PP & -0.199 & 0.0094 \\
& IGF-I vs. POP & -0.306 & 0.000065 \\
& BHBA vs. PA & 0.212 & 0.0049 \\
& BHBA vs. PP & 0.199 & 0.0087 \\
\hline
\end{tabular}

${ }^{1} \mathrm{PA}=$ phagocytic activity; $\mathrm{PC}=$ phagocytic capacity; $\mathrm{PP}=$ phagocytic power; $\mathrm{POP}=$ phagocytic overall performance.

numbers of neutrophils dropped again in both animal groups (Figure 2a). The mean number of phagocytosed bacteria per cell (Figure 2c) was found to be more or less constant or fluctuated in a narrower range; this indicates either that a higher fraction of cow neutrophils (compared with the fraction of heifer neutrophils) are equipped with phagocytosis-relevant receptors (e. g., C3b-receptors, Fc-receptors) or that the sera of cows contain more opsonizing factors in blood plasma than do the sera of heifers.

The significantly higher PA in pluriparous cows compared with that of primiparous cows in wk 2 and 3 after calving was in contrast to results reported by Mehrzad et al. (2009) showing a pronounced decrease in phagocytosis of Staph. aureus in PMNL from pluriparous cows compared with those of primiparous cows. This contradiction may be explained by different approaches to investigate PA. In contrast to Mehrzad et al. (2009) who added pooled bovine serum to purified PMNL and bacteria, we used a whole blood assay and, thus, the PA of individuals depended not only on the intrinsic activity of the phagocytic cells but also on the phagocytosis-enhancing factors (e.g., antibodies, complement factors) in the plasma of individuals. Although we did not further analyze plasma concentrations of opsonizing factors, it seems reasonable to suggest that pluriparous cows have higher respective plasma levels resulting in a higher PA compared with that of primiparous cows.

Differences between primiparous and pluriparous cows were even more pronounced when considering the PC (depicting the mean fluorescence value of PMNL which had phagocytosed). Compared with rather constant values in pluriparous cows, a significant decrease in $\mathrm{PC}$ occurred in primiparous cows around calving. 
Thus, not only the fraction of PMNL that phagocytosed, but also the numbers of phagocytosed bacteria per cell were significantly lower in primiparous cows.

Phagocytosis assessed in whole blood assays ex vivo is affected not only by PA and PC, but also by the number of PMNL (Figure 2a). Thus, we also calculated the POP taking all these parameters into account. This analysis demonstrated that pluriparous and primiparous cows did not differ with respect to PMNL function in the week of calving. In primiparous cows, apparently lower PA and PC were compensated by higher blood PMNL numbers. The differences between primiparous and pluriparous cows regarding $\mathrm{PA}, \mathrm{PC}$, and number of PMNL suggest that it is insufficient to determine only one parameter to assess PMNL function.

\section{PMNL Function and Blood Metabolites}

The transition from pregnancy to lactation is marked by various changes of serum metabolite and hormone concentrations. Whether blood metabolites affect the function of PMNL effector cells has been addressed in several studies with midlactation cows and cows in the transition period (Loiselle et al., 2009; Moyes et al., 2009). Whereas in midlactation cows, NEFA and BHBA concentrations were negatively correlated with PMNL phagocytosis rates (Moyes et al., 2009), Loiselle et al. (2009) found no significant correlations in pluriparous cows during the transition period. These unclear relationships between NEFA/BHBA and PMNL function were also reflected in the present study in which primiparous and pluriparous cows had divergent correlations (Table 1). Whereas BHBA concentrations correlated positively with the $\mathrm{PP}$ and $\mathrm{PA}$ in the transition period of pluriparous cows, neither positive nor negative correlations were seen in primiparous cows. This could indicate that other metabolites and hormones act in concert to modulate the function of PMNL.

Because IGF-I is an important growth factor and was already shown to influence PMNL function in vitro (Bjerknes and Aarskog, 1995; Balteskard et al., 1998; Inoue et al., 1998; Kooijman et al., 2002; Wathes et al., 2009; Zhao et al., 2009), we determined whether changes of total IGF-I in serum were correlated with PMNL function. The difference between IGF-I concentrations in primi- and pluriparous cows was lower than expected and may have accounted for the lack of significant differences in PA or PC of PMNL. Interestingly, all peripartal changes of all parameters assessed to describe phagocytic PMNL function differed markedly from the concomitant changes in plasma IGF-I concentrations. In general, higher IGF-I concentrations seemed to correlate with decreased PMNL functions, especially in pluriparous cows when looking at the whole transition period (Table 1). These negative relations between IGF-I concentrations and PMNL functions were rather weak, leading us to infer that IGF-I plasma concentrations were not very indicative of altered PMNL functions.

The lack of positive correlations between IGF-1 concentration and PMNL parameters was supported by findings of Hoeben et al. (2000) who treated cows with bovine somatotropin, which increased plasma IGF-I concentration significantly. However, no effect on the generation of reactive oxygen species by PMNL and no migration-enhancing effects were detected. Studies with other species also suggested that treatment with IGF-I had no enhancing, and even a suppressing, effect on the phagocytic function of ex vivo analyzed PMNL (e.g., in pigs; Balteskard et al., 1998), which was partially consistent with our observations. A suppressing effect of IGF-I on phagocytic performance in pluriparous cows in the transition period was inferred, based on weak negative correlations between IGF-I and PMNL number, PP, PA, and POP. However, during the transition period, the somatotropic axis is uncoupled and liver-derived IGF-I decreases, whereas growth hormone (GH) increases (Lucy, 2008). In vitro, GH increased PC (Inoue et al., 1998) but treatment of cows with recombinant bovine somatotropin during experimentally induced mastitis seemed not to affect chemiluminescence, diapedesis, or expression of adhesion receptors in vivo (Hoeben et al., 1999). In that study, increased plasma concentrations of both GH and IGF-I were observed. The physiological situation around calving is, however, accompanied by low IGF-I and elevated GH concentrations. Pluriparous cows with lower IGF-I concentrations postpartum may have higher GH concentrations but the correlation between GH and functionality of PMNL was not addressed in the present study. The ex vivo findings of the effects of IGF-I on PMNL function were in contrast to the reported effects of enhanced PMNL function in vitro when free IGF-I was added $(\mathrm{Fu}$ et al., 1991; Bjerknes and Aarskog, 1995; Balteskard et al., 1998; Inoue et al., 1998). The apparent discrepancy between in vitro and our ex vivo results with respect to the role of IGF-I for PMNL function may be due to the dose-effect relation. Physiological concentrations of in vitro-added IGF-I primed PMNL for an enhanced generation of reactive oxygen species (Fu et al., 1991). In studies revealing an enhancing effect of IGF-I on phagocytosis, 100- to 1,000-fold higher free IGF-I concentrations (e.g., 5,000 ng/mL, Balteskard et al., 1998; or $1,000 \mathrm{ng} / \mathrm{mL}$, Inoue et al., 1998) than physiologically found in plasma (approximately 1\% of total IGF-I is free; Figure 1a) were used. Thus, the addition of free IGF-I to in vitro culture medium seemed inappropriate as a model of the situation in vivo, where at least 
$99 \%$ of IGF-I is bound to IGF-binding protein 3, leaving only small fraction (approximately $0.9 \mathrm{ng} / \mathrm{mL}$ ) of free IGF-I (Denley et al., 2005). Thus, POP from cows with physiological total IGF-I concentrations (bound and free IGF-I) around calving seemed more consistent with physiological actions of IGF-I in whole blood assays. Determining PA and PC, and moreover POP, from whole-blood assays containing physiological levels of both IGF-I, NEFA, and BHBA, may provide more biologically relevant information regarding their effects on PMNL function in vivo.

\section{CONCLUSIONS}

The POP of PMNL is a derived parameter characterizing the proportion of PMNL that is able to phagocytose and the performance of PMNL in a given time frame. The whole-blood assay together with the flow cytometric evaluation indicates that the peripheral pool of PMNL is less suppressed regarding phagocytosis at the time of calving than previously assumed. A decrease in $\mathrm{PC}$ of the PMNL population is compensated by higher numbers of available PMNL. The IGF-I concentrations were correlated with an enhanced POP of PNML from primiparous and pluriparous cows. Weak negative correlations with single PMNL phagocytosis parameters were mainly observed when looking at the whole transition period. Thus, plasma IGF-I concentration can not be regarded as a suitable predictor for the ability of bovine blood PMNL to phagocytose bacteria.

\section{REFERENCES}

Balteskard, L., K. Unneberg, D. Halvorsen, J. B. Hansen, and A. Revhaug. 1998. Effects of insulin-like growth factor 1 on neutrophil and monocyte functions in normal and septic states. JPEN J. Parenter. Enteral Nutr. 22:127-135.

Bell, A. W. 1995. Regulation of organic nutrient metabolism during transition from late pregnancy to early lactation. J. Anim. Sci. 73:2804-2819.

Bjerknes, R., and D. Aarskog. 1995. Priming of human polymorphonuclear neutrophilic leukocytes by insulin-like growth factor I Increased phagocytic capacity, complement receptor expression, degranulation, and oxidative burst. J. Clin. Endocrinol. Metab. 80:1948-1955.

Boisclair, Y. R., D. E. Bauman, A. W. Bell, F. R. Dunshea, and M. Harkins. 1994. Nutrient utilization and protein turnover in the hindlimb of cattle treated with bovine somatotropin. J. Nutr. 124:664-673

Burvenich, C., D. D. Bannerman, J. D. Lippolis, L. Peelman, B. J. Nonnecke, M. E. Kehrli Jr., and M. J. Paape. 2007. Cumulative physiological events influence the inflammatory response of the bovine udder to Escherichia coli infections during the transition period. J. Dairy Sci. 90(Suppl. 1):E39-E54.

Denley, A., L. J. Cosgrove, G. W. Booker, J. C. Wallace, and B. E. Forbes. 2005. Molecular interactions of the IGF system. Cytokine Growth Factor Rev. 16:421-439.

Fu, Y. K., S. Arkins, B. S. Wang, and K. W. Kelley. 1991. A novel role of growth hormone and insulin-like growth factor-I. Priming neutrophils for superoxide anion secretion. J. Immunol. 146:16021608.
Hammon, D. S., I. M. Evjen, T. R. Dhiman, J. P. Goff, and J. L. Walters. 2006. Neutrophil function and energy status in Holstein cows with uterine health disorders. Vet. Immunol. Immunopathol. $113: 21-29$

Hoeben, D., C. Burvenich, P. J. Eppard, J. C. Byatt, and D. L. Hard. 1999. Effect of bovine somatotropin on neutrophil functions and clinical symptoms during Streptococcus uberis mastitis. J. Dairy Sci. $82: 1465-1481$.

Hoeben, D., E. Monfardini, G. Opsomer, C. Burvenich, H. Dosogne, A. De Kruif, and J. F. Beckers. 2000. Chemiluminescence of bovine polymorphonuclear leucocytes during the periparturient period and relation with metabolic markers and bovine pregnancyassociated glycoprotein. J. Dairy Res. 67:249-259.

Hogan, J. S., K. L. Smith, W. P. Weiss, D. A. Todhunter, and W. L. Schockey. 1990. Relationships among vitamin E, selenium, and bovine blood neutrophils. J. Dairy Sci. 73:2372-2378.

Inoue, T., H. Saito, T. Matsuda, K. Fukatsu, I. Han, S. Furukawa, S. Ikeda, and T. Muto. 1998. Growth hormone and insulin-like growth factor I augment bactericidal capacity of human polymorphonuclear neutrophils. Shock 10:278-284.

Kawashima, C., S. Fukihara, M. Maeda, E. Kaneko, C. A. Montoya, M. Matsui, T. Shimizu, N. Matsunaga, K. Kida, Y. Miyake, D. Schams, and A. Miyamoto. 2007. Relationship between metabolic hormones and ovulation of dominant follicle during the first follicular wave post-partum in high-producing dairy cows. Reproduction 133:155-163.

Kehrli, M. E., B. J. Nonnecke, and J. A. Roth. 1989. Alterations in bovine neutrophil function during the periparturient period. Am. J. Vet. Res. 50:207-214.

Kooijman, R., A. Coppens, and E. Hooghe-Peters. 2002. Igf-I inhibits spontaneous apoptosis in human granulocytes. Endocrinology 143:1206-1212.

Lamote, I., E. Meyer, L. Duchateau, and C. Burvenich. 2004. Influence of 173 -estradiol, progesterone, and dexamethasone on diapedesis and viability of bovine blood polymorphonuclear leukocytes. J. Dairy Sci. 87:3340-3349.

Littell, R. C., P. R. Henry, and C. B. Ammerman. 1998. Statistical analysis of repeated measures data using SAS procedures. J. Anim. Sci. 76:1216-1231.

Loiselle, M. C., C. Ster, B. G. Talbot, X. Zhao, G. F. Wagner, Y R. Boisclair, and P. Lacasse. 2009. Impact of postpartum milking frequency on the immune system and the blood metabolite concentration of dairy cows. J. Dairy Sci. 92:1900-1912.

Lucy, M. C. 2000. Regulation of ovarian follicular growth by somatotropin and insulin-like growth factors in cattle. J. Dairy Sci. 83:1635-1647.

Lucy, M. C. 2008. Functional differences in the growth hormone and insulin-like growth factor axis in cattle and pigs: Implications for post-partum nutrition and reproduction. Reprod. Domest. Anim. 43:31-39.

Madsen, S. A., P. S. Weber, and J. L. Burton. 2002. Altered expression of cellular genes in neutrophils of periparturient dairy cows. Vet. Immunol. Immunopathol. 86:159-175.

Mallard, B. A., L. C. Wagter, M. J. Ireland, and J. C. Dekkers. 1997. Effects of growth hormone, insulin-like growth factor-I, and cortisol on periparturient antibody response profiles of dairy cattle. Vet. Immunol. Immunopathol. 60:61-76.

Meglia, G. E., A. Johannisson, S. Agenäs, K. Holtenius, and K. P. Waller. 2005. Effects of feeding intensity during the dry period on leukocyte and lymphocyte sub-populations, neutrophil function and health in periparturient dairy cows. Vet. J. 169:376-384.

Mehrzad, J., L. Duchateau, and C. Burvenich. 2009. Phagocytic and bactericidal activity of blood and milk-resident neutrophils against Staphylococcus aureus in primiparous and multiparous cows during early lactation. Vet. Microbiol. 134:106-112.

Mehrzad, J., L. Duchateau, S. Pyorala, and C. Burvenich. 2002. Blood and milk neutrophil chemiluminescence and viability in primiparous and pluriparous dairy cows during late pregnancy, around parturition and early lactation. J. Dairy Sci. 85:3268-3276.

Moyes, K. M., J. K. Drackley, J. L. Salak-Johnson, D. E. Morin, J. C. Hope, and J. J. Loor. 2009. Dietary-induced negative energy bal- 
ance has minimal effects on innate immunity during a Streptococcus uberis mastitis challenge in dairy cows during midlactation. J. Dairy Sci. 92:4301-4316.

Piepers, S., G. Opsomer, E. Meyer, K. Demeyere, H. W. Barkema, A. de Kruif, and S. De Vliegher. 2009. Heifer and quarter characteristics associated with periparturient blood and milk neutrophil apoptosis in healthy heifers and in heifers with subclinical mastitis. J. Dairy Sci. 92:4330-4339

Scalia, D., N. Lacetera, U. Bernabucci, K. Demeyere, L. Duchateau, and C. Burvenich. 2006. In vitro effects of nonesterified fatty acids on bovine neutrophils oxidative burst and viability. J. Dairy Sci 89:147-154.

Sheldon, I. M., J. Cronin, L. Goetze, G. Donofrio, and H. J. Schuberth. 2009. Defining postpartum uterine disease and the mechanisms of infection and immunity in the female reproductive tract in cattle. Biol. Reprod. 81:1025-1032.

Smits, E., C. Burvenich, and R. Heyneman. 1997. Simultaneous flow cytometric measurement of phagocytotic and oxidative burst activity of polymorphonuclear leukocytes in whole bovine blood Vet. Immunol. Immunopathol. 56:259-269.
Taylor, V. J., Z. Cheng, P. G. Pushpakumara, D. E. Beever, and D. C. Wathes. 2004. Relationships between the plasma concentrations of insulin-like growth factor-I in dairy cows and their fertility and milk yield. Vet. Rec. 155:583-588.

Van Kampen, C., and B. A. Mallard. 1997. Effects of peripartum stress and health on circulating bovine lymphocyte subsets. Vet. Immunol. Immunopathol. 59:79-91.

Wathes, D. C., Z. Cheng, W. Chowdhury, M. A. Fenwick, R. Fitzpatrick, D. G. Morris, J. Patton, and J. J. Murphy. 2009. Negative energy balance alters global gene expression and immune responses in the uterus of postpartum dairy cows. Physiol. Genomics 39:1-13.

Zerbe, H., N. Schneider, W. Leibold, T. Wensing, T. A. Kruip, and H. J. Schuberth. 2000. Altered functional and immunophenotypical properties of neutrophilic granulocytes in postpartum cows associated with fatty liver. Theriogenology 54:771-786.

Zhao, J., N. Harada, K. Sobue, H. Katsuya, and K. Okajima. 2009. Insulin-like growth factor-I reduces stress-induced gastric mucosal injury by inhibiting neutrophil activation in mice. Growth Horm. IGF Res. 19:136-145. 